\title{
Adaptive minirhizotron for pepper roots observation and its installation based on root system architecture traits
}

\author{
Wei Lu' ${ }^{1}$, Xiaochan Wang ${ }^{1,2^{*}}$ and Fengjie Wang ${ }^{1}$
}

\begin{abstract}
Background: Root is the principal part of plants to absorb water and nutrient, anchor the plant and affect yield and quality. Non-destructive detection of root traits is difficult to perform due to the hidden nature of the root. Therefore, improved methods to measure roots are necessary to support plant breeding, and optimization of cultivation and management. In this study, we present an adaptive minirhizotron along with installation patterns to focus on micro and local changes in multipoint of pepper roots.
\end{abstract}

Results: The method is to improve minirhizotron by reducing its size to a microrhizotron $(1.1 \times 1.1 \times 1.2 \mathrm{~cm})$ and improving installation validity and rationality according to spatial distribution characteristics of Capsicum annuum root system. This adaptive minirhizotron could acquire root image in multipoint, and through image processing, root traits such as root length (including very fine roots or root hairs) and root width could be calculated. In order to install the microrhizotron reasonably and effectively, root system architecture (Capsicum annuum) was reconstructed using a three-dimensional caliper, and were quantified in circumferential distribution, vertical direction and root extension. The results showed that most lateral roots were constrained to $45^{\circ}$ in horizontal direction to root initial position; Vertical angles were large, almost perpendicular to the root center line at initial position, and it became smaller when roots began to deepen. Root length density decreased with the increase of distance to plant center. According to Capsicum annuum root system traits, totally 8 installation methods were tested and verified to determine high probability of root interception. Horizontal angle $45^{\circ}$ showed much higher interception probability than that of $90^{\circ}$. Vertical angle $45^{\circ}$ has slightly higher root interception probability than that of $30^{\circ}$. Installation pattern horizontal angle $45^{\circ}+$ radius $30 \mathrm{~mm}+$ vertical angle $45^{\circ}$ showed the best performance in root interception with probability of $96.7 \%$, followed by pattern horizontal angle $45^{\circ}+$ radius $30 \mathrm{~mm}+$ vertical angle $30^{\circ}$. Comparison experiment showed that when root hair and very fine root were excluded, relative error was $12.1 \%$ between microrhizotron and soil sampling in root length, and $15.4 \%$ in root diameter. Microrhizotron was able to observe fine roots about $0.1 \mathrm{~mm}$ in diameter.

Conclusion: A new adaptive minirhizotron has been established for nondestructive observation on local and micro changes of roots in multipoint, and its application and installation patterns has been suggested according to root architecture traits. The microrhizotron can be used to study a wide range of research questions focused on quantitative trait locus analysis, root width changes, and root hair growth.

Keywords: Adaptive minirhizotron, Pepper roots, Root 3D reconstruction, Root analysis, Installation patterns, Root observation

\footnotetext{
*Correspondence: wangxiaochan@njau.edu.cn

${ }^{1}$ Department of Engineering College, Nanjing Agricultural University,

Nanjing 210031, China

Full list of author information is available at the end of the article
} 


\section{Background}

Being the principal water and nutrition absorbing organ, root plays a very important role in anchor of plants, uptake of water and nutrient, and affecting crop yield and quality. The study of root morphology is the most important content in plant nutrition, plant physiology, breeding, and ecology [1, 2]. Accurate acquisition of root morphology in real time is the prerequisite and key step to gene improvement, water and fertilizer utilization efficiency, and crop quality and yield in agricultural production [3]. Due to the opacity and complexity of root growth environment, the research progress of roots is relatively slow. Traditional methods (excavation, profile, soil column, etc.) are mostly destructive or have changed the original growth environment of crops (hydroponics, fogging), and the test results are not of universality [4-6].

With the development of computer technology and nondestructive testing technology, methods such as $\mathrm{X}$-ray computed tomography $(\mathrm{X}-\mathrm{CT})$, radioisotope tracing, nuclear magnetic resonance (NMR) and minirhizotron have been developed [7-9]. X-CT, radioisotope tracing, and NMR were expensive, difficult to operate, and can only be measured in a laboratory environment, so they have not been widely used currently [7, 9-13]. Minirhizotron, first described by Bates in 1937, was a kind of nondestructive method to observe roots at a particular point throughout the growing period [14-16]. Since then, a lot of researches such as forest, orchard, agroecosystem and other areas have been carried out based on application of minirhizotron [17-21]. Upchurch [22] used a low-light monochromatic camera to conduct in situ root observation through a transparent acrylic canal, which proved that this method has a linear relationship with the soil sampling method. Liao [23] used minirhizotron observation method to track and monitor the root growth dynamics of maize over a period of time, and also showed that this method was in good agreement with soil sampling method.

Minirhizotron, to some extent, provided a method of observing roots over a long period of time [24, 25]. However, many studies have shown that application of minirhizotron disturbed both the roots and the soil [26, 27]. Joslin [28] showed that installation of minirhizotron resulted in excessive root proliferation, particularly near the soil surface, and it would take about 2 years for the trees to return to a new equilibrium. Itoh [29] proved that root growth path was changed with the installation of minirhizotron tube, and the correlation between root length density and real value became small with the increase of tube diameter. In addition, the installation of minirhizotron may cause problems such as affecting the compactness of soil and introducing light; the material of minirhizotron may disturb roots and soil; traditional minirhizotron also had difficulty in accurate observation of fine roots $[18,30,31]$. Therefore, the improved minirhizotron technology emerged as required.

Amato [32] developed a high quality low-cost digital microscope minirhizotron system with an amplifier and provided detailed building process. Cai [33] used acrylic glass, which had higher hardness, higher transparency, and less effect on root growth, proposed a method of installing minirhizotron tubes without digging soil so that root development could be monitored in naturally structured soils. Traditional research assumed that it was visible for cameras in the minirhizotron within $2-3 \mathrm{~mm}$ of soil $[8,22,34]$. But Taylor et al. believed that this assumed value was so large that the measured root diameter may well be smaller than the true value. His empirical algorithm assumed that the visible thickness is only $0.78 \mathrm{~mm}$, and his method improved the accuracy of root diameter and biomass with captured images [26]. These methods mainly focused on the installation, image processing methods, and size and materials of minirhizotron. However, it is rarely reported that biological characteristics and spatial distribution characteristics of root system taken into account along with adaption of minirhizotron, to monitor roots effectively and reasonably.

In this paper, we explore how to improve the use of minirhizotron from two aspects: reducing the size of minirhizotron and improving installation validity and rationality with biological characteristics and spatial distribution characteristics of root system (Capsicum ann$u u m)$. A kind of adaptive minirhizotron (microrhizotron) and processing systems, $1.5 \mathrm{~cm}^{3}$ in volume, was designed to observe roots dynamically. This microrhizotron system was able to focus on local and micro root changes in situ fast and accurate, and it can be used to observe roots in multiple points, which will provide more detail changes of roots in different points reliably for plant nutrition, plant physiology and ecology.

\section{Material and method}

Plant materials and growth conditions

Capsicum annuum (Bell Pell, Shouhe Co., Ltd, Shandong, China) seeds were sown in plug tray containing cultivated soil (organic matter: $478 \mathrm{~g} / 1000 \mathrm{~g}, \mathrm{~N}+\mathrm{P}+\mathrm{k}$ : $6.75 \mathrm{mg} / 1000 \mathrm{~g}$, probiotics: $90 \mu \mathrm{g} / 1000 \mathrm{~g}$, trace element: $1.7 \mu \mathrm{g} / 1000 \mathrm{~g}$, humic acid: $130 \mu \mathrm{g} / 1000 \mathrm{~g}, \mathrm{pH} 6.5-6.8$ ). After germinating in greenhouse in Nanjing Agricultural University, Engineering College $\left(32^{\circ} 18^{\prime} \mathrm{N}, 118^{\circ} 46^{\prime} \mathrm{E}\right)$ for 18 days, pepper seedlings with two true leaves were transplanted to 3 experimental pots $(1.2 \mathrm{~m} \times 1.2 \mathrm{~m} \times 0.4 \mathrm{~m})$. The plant spacing was $25 \mathrm{~cm}$ and each plant was irrigated uniformly of $200 \mathrm{ml}$ water every day with sprinkle from the field planting day. The soil (brown clay soil, organic matter: $318 \mathrm{~g} / 1000 \mathrm{~g}$, total $\mathrm{N}: 1.6 \mathrm{~g} / 1000 \mathrm{~g}$ ) in the pots 
was taken from local vegetable growing area, and was filtered 3 times with $1 \mathrm{~cm}$ opening to filter soil blocks larger than $1 \mathrm{~cm}^{3}$. The soil compaction was $0.81 \mathrm{~kg} / \mathrm{cm}^{2}$ at the field planting day.

In the first experiment (root architecture 3D reconstruction), plants were sampled in 7 days, 13 days, 19 days, 25 days, 31 days and 39 days after field planting, 3 replicates. In the second experiment (interception probability in different installation patterns), there were totally 8 installation patterns, 12 replicates. In the third experiment (comparing the microrhizotron with soil sampling), 16 samples were used to compare microrhizotron obtained root indicators with manual measured root indicators.

\section{Adaptive minirhizotron}

Since traditional minirhizotron was always large in diameter, it was not suitable to detect roots of shallow plant like peppers, which might cause great effects on root development. In order to observe roots development of shallow root plant in real time and multiple points, a kind of micro acquisition and processing system (mcrorhizotron) for multiple roots observation was proposed and designed in this paper.

The mcrorhizotron consisted of a micro camera (HDMINICAM, Guangdong, China), an optical amplifier (amplified by 20 times), LED, a power supply and wireless module integrated in the camera, and image processing part (Fig. 1). The camera is 12 million pixel CMOS (complementary metal oxide semiconductor), resolution $1080 \mathrm{p}$, angle of view $120^{\circ}$, working temperature $-20{ }^{\circ} \mathrm{C}$ $-80{ }^{\circ} \mathrm{C}$, relative humidity $15-85 \%$. Four LED light sources were installed on the top of the microrhizotron to illuminate imaging area. In order to prevent short circuit troubles, the circuit part of the system was sealed with hot melt glue and sprayed with waterproof paint for circuit board (A-2577, China) [35]. The size of the system was $1.1 \mathrm{~cm} \times 1.1 \mathrm{~cm} \times 1.2 \mathrm{~cm}$. The collected root image was transmitted to the terminal receiving device (mobile phone or personal computer) through the WIFI signal formed by the wireless control module (Model: MEDIATEK MT7601).

\section{Image processing}

The JPEG files that contained the images of roots were used to determine the root length (including root hair and very fine roots) and root diameter. The root image was preprocessed through image normalization, enhancement, and median filter, and then through image morphology operation, skeleton image in single pixel were extracted [36, 37] as is shown in Fig. 2. In Fig. 2a1, a3 were the same root with different root hair or fine roots observed in different days. Figure 2a2, a4 were extracted root skeleton in single pixel. It was obvious that Fig. 2a2 had more and longer root hair or fine roots than that of Fig. 2a4. Root length was measured through calculating connections between adjacent pixels including diagonal connection or straight-line connection in skeleton image [37]. If two adjacent pixels is straight-line connection, the distance between the two pixels is 1 ; if it is diagonal connection, the distance is $\sqrt{2}$. Code and script were developed by authors. However, in this way of automatic calculation, both the root axes and very fine root (root hairs) were included. And in root images (Fig. 2), fine root (root hairs) composed the most part. In order to analyze different root traits and to improve measuring accuracy, root axes and root hairs should be separated. Therefore, after the total root length was calculated automatically in skeleton image, root axes length was measured using ruler tools in Adobe Photoshop CS6 Extended. Root surface area was measured by counting the root pixels and calculating total area by multiplying
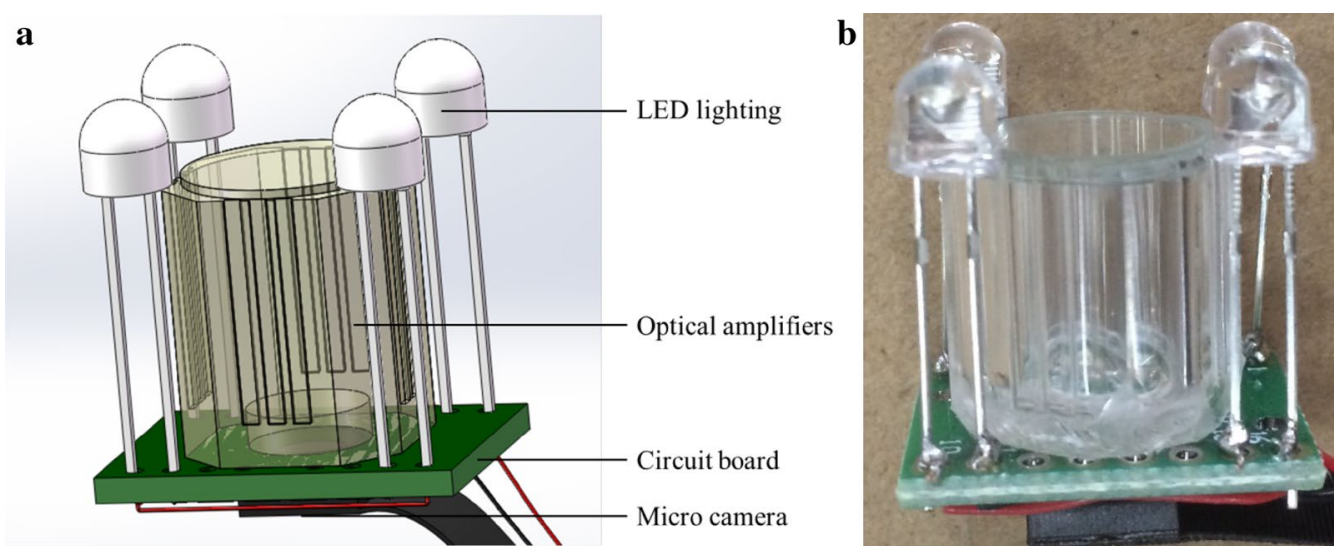

Fig. 1 Structure diagram and photo of micro root observation system. a Structure diagram of microrhizotron. b Picture of microrhizotron 

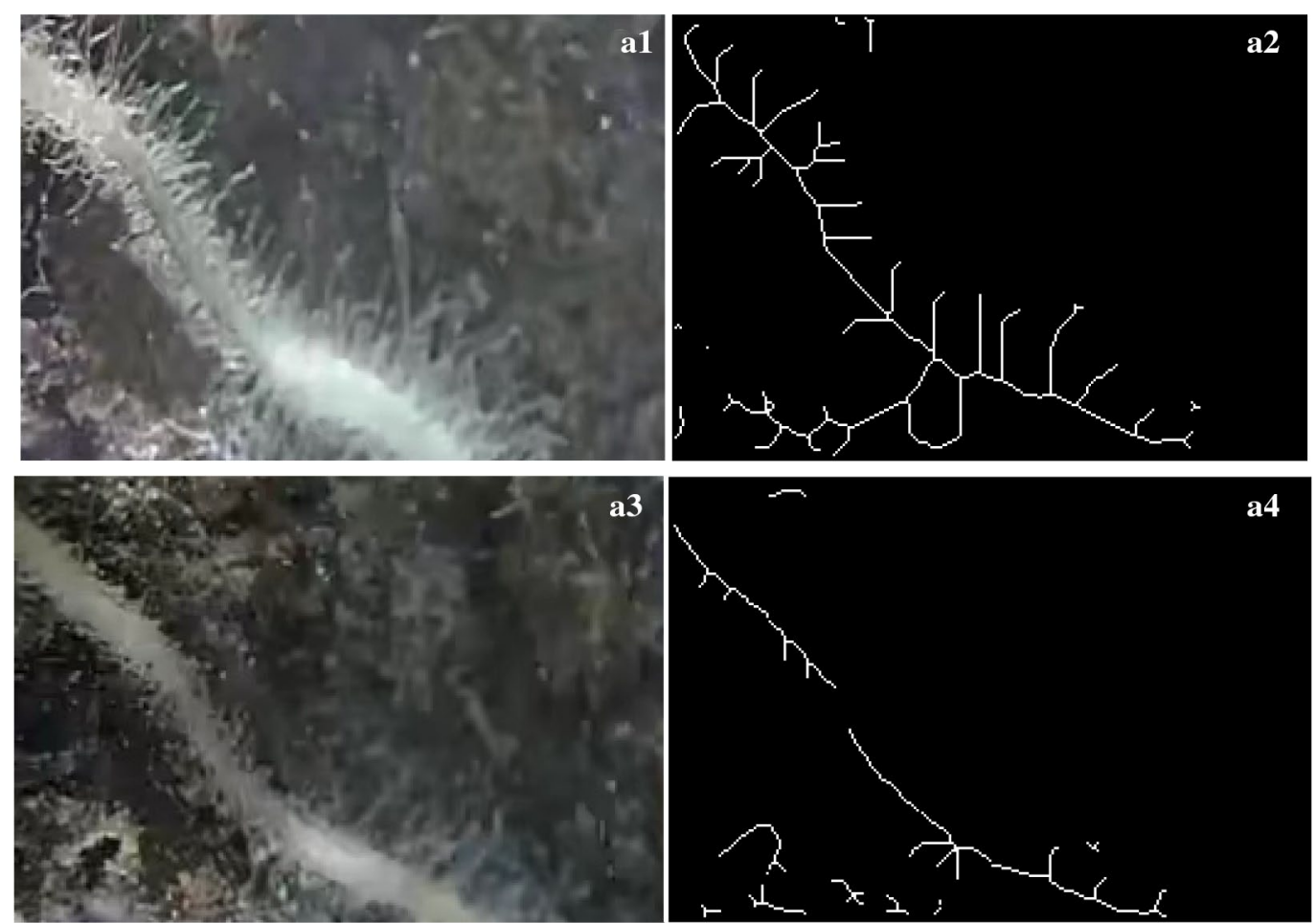

Fig. 2 Source picture and processed image of roots. a1 Source picture of roots observed in 28 days. a2 Skeleton of a1. a3 Source picture of roots observed in 60 days. a4 Skeleton of a3

area of each pixel based on the segmented binary image [35]. Root length and diameter was calculated by:

$$
\begin{aligned}
& l=\left(\sqrt{2} N_{1}+N_{2}\right) K / \mathrm{f} \\
& S_{r}=K \times P / f \\
& d=S_{r} / l
\end{aligned}
$$

where $\mathrm{l}$ is root length, $S_{r}$ is root surface area, $\mathrm{f}$ is the magnification of the optical element, $\mathrm{P}$ is the total number of root pixels, $\mathrm{K}$ is the corresponding relation between the pixel distance on the image and the actual pixel distance, $\mathrm{d}$ is mean root diameter. $\mathrm{N} 1$ represents the number of pixels connected diagonally, and $\mathrm{N} 2$ represents the number of pixels connected horizontally and vertically (Additional files 1,2).

\section{Root architecture 3D reconstruction and spatial distribution analysis}

The root samples were excavated using a columnar sampler every 7 days ( 10 days after field planting, taking the center of the plant root system as the center, $10 \mathrm{~cm}$ as the radius (Fig. 3a)). The root architecture was measured using a three-dimensional caliper as shown in Fig. 3b. This instrument was mainly composed of

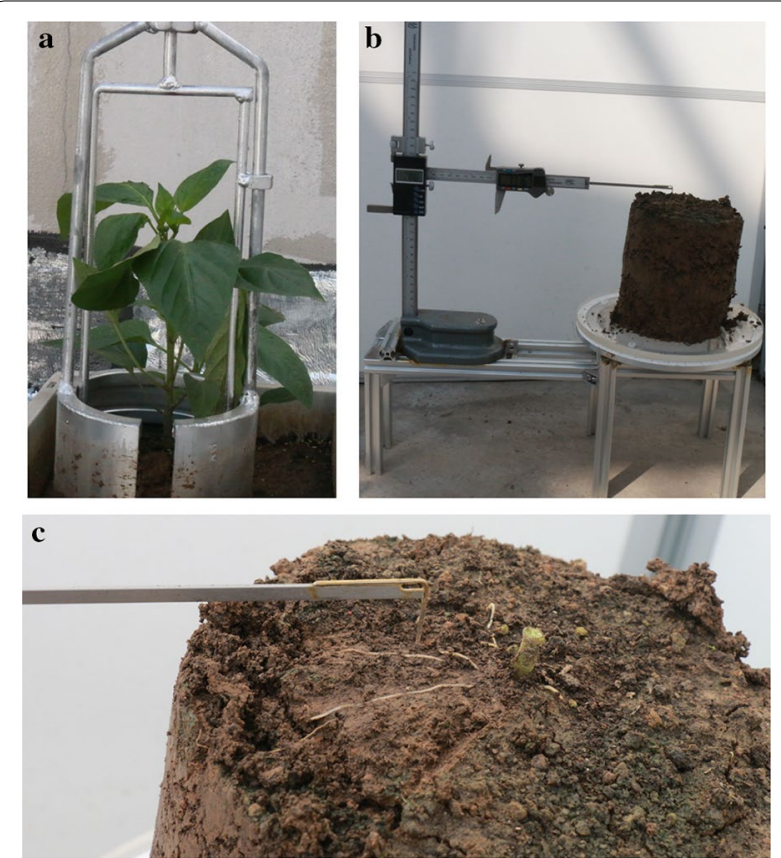

Fig. 3 Root spatial structure measuring instrument. a Sampling of pepper roots. $\mathbf{b}$ Measuring instrument. c Measurement of lateral roots architecture 
height ruler, horizontal direction ruler, rotating disk ruler and laser centering device. First, the sample of the soil column and rotating disk were centered with a line laser, and then the top soil was gently removed with a small brush from the upper layer. The underlying soil of the root was preserved to make the root attached to it, so as not to destroy the original spatial position. The exposed root was measured with the tip of the threedimensional caliper at each $2-3 \mathrm{~mm}$ interval, and it was cut off from the base after the last point was measured (Fig. 3c). The measured data were transformed from cylindrical coordinate system to Cartesian coordinate system, and the root system was reconstructed and analyzed with Matrix laboratory (version: 7.11.0.584). The code or script was developed by author.
Roots of capsicum belong to diarch, and the lateral roots initiate from two opposite poles of protoxylem pole pericycle cell. Lateral roots are generally spaced along the longitudinal axis of the main root. Although it has long been known that lateral roots are symmetrically located, the spatial distribution of lateral roots after elongation remains unknown. In order to figure out root system architecture traits, the spatial structure after root elongation was further analyzed in circumferential direction, radial direction, and vertical direction (Fig. 4). $\alpha$ was used to characterize the angular change in the vertical direction, and it was the angle between lateral root (each elongation of $20 \mathrm{~mm}$ ) and plant center line. $\mathrm{L}$ was used to characterize the circumferential spreading length of lateral roots, and it was the distance between lateral root a

$90^{\circ}$

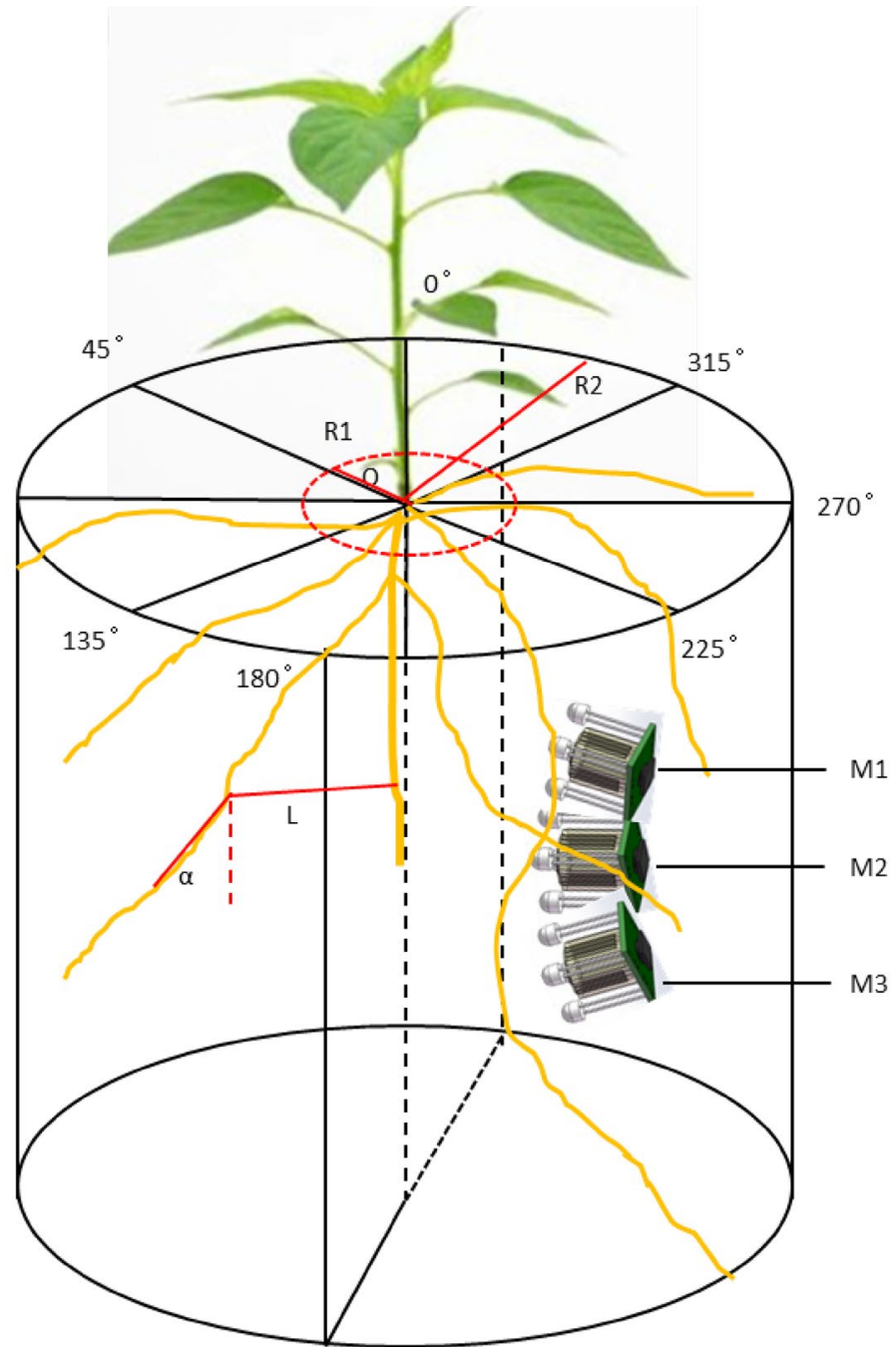

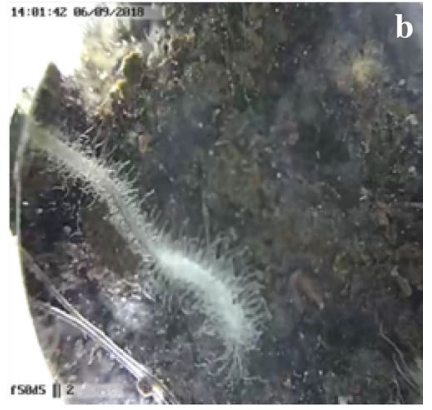
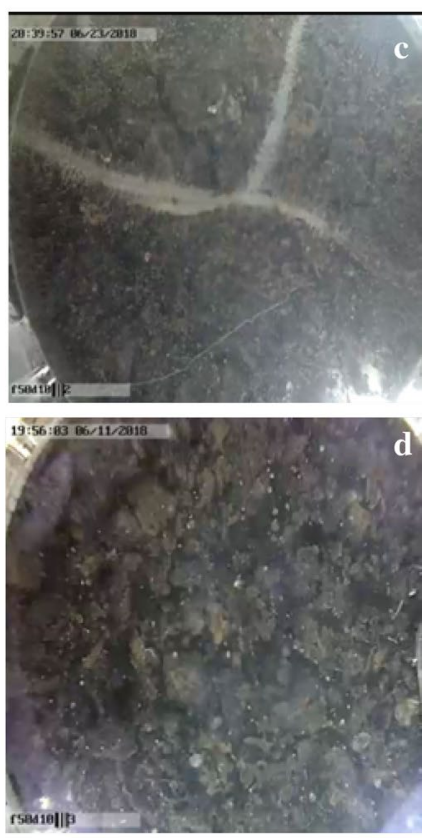

Fig. 4 Installation patterns of microrhizotrons. a Installation patterns of microrhizotrons. M1, M2, M3 are microrhizotrons in different vertical angles and depth. $\boldsymbol{a}$ is vertical angle, $\mathrm{L}$ is lateral roots extension, and R1 and R2 are root length density sampling radius. $\mathbf{b}, \mathbf{c}$, and $\mathbf{d}$ Roots images from M1, $\mathrm{M} 2$ and $\mathrm{M} 3$ 
(each elongation of $30 \mathrm{~mm}$ ) and plant center line in horizontal direction.

Root length density was calculated every $\mathrm{R}=10 \mathrm{~mm}$ radically by the formula as follows:

$$
\mathrm{RLD}=\frac{\sum_{i=1}^{n} l_{i}}{V}
$$

where RLD is root length density, $l_{i}$ is length of root $\mathrm{i}$, and $\mathrm{V}$ is volume of the soil with roots.

\section{Installation validity and rationality of microrhizotron}

In order to reduce the disturbance caused by installation, the microrhizotrons were presetted at the field planting day. $1.5 \mathrm{~cm}^{3}(1.1 \times 1.1 \times 1.2 \mathrm{~cm})$ of soil was removed (replaced by microrhizotron), and the camera of the micro observation system was set carefully towards the roots. The rest of the soil was covered and compacted gently by rubber hammer to ensure that the soil compactness was consistent with the original growing soil environment. We declared a root interception success when the captured root length (root diameter) increased or decreased between $t$ day and $t+1$ day.

As is shown in Fig. 4, there were a lot of possibilities to set microrhizotrons. Circumferential position around the plant, installation radiuses of microrhizotron to the root center line, vertical angle and depth may all contribute to the effectiveness of microrhizotrons. For example, M1, M2 and M3 were set at random into soil. M1 was able to intercept with roots, and M2 would intercept with more; but M3 was further from roots, so this set of microrhizotron might be invalid in observing roots. Therefore, to improve the capture of roots, microrhizotrons should be presetted reasonably. And our solution was to install microrhizotrons based on biological characteristics and spatial distribution characteristics of root system, including determining optimal circumferential position, radical position and vertical angle.

\section{Comparing the microrhizotron with soil sampling}

Comparison experiment was conducted with soil sampling using the microrhizotron developed. In the experiment, each plant was installed with 2 microrhizotrons (opposite) in installation pattern horizontal angle $45^{\circ}+$ radius $30 \mathrm{~mm}+$ vertical angle $45^{\circ}$ (depth $50 \mathrm{~mm}$ ) with 16 replicates. At four dates, root image was captured and processed by microrhizotron system. At the same time, soil samples were extracted with a cut syringe (diameter $2 \mathrm{~cm}$ ) as is shown in Fig. 5. The syringe was used to extract soil cylinder opposite the camera. After the soil cylinder together with the microrhizotron was extracted, they were carefully put out and cut off layer by layer until $3 \mathrm{~mm}$ to the camera $[24,25]$, thus the roots in the view of camera was acquired. The roots were then washed carefully with distilled water and wiped with absorbent paper, and then measured root length and diameter manually with microcallipe.

\section{Results}

Three-dimensional reconstruction of capsicum root system Root 3D reconstruction for $4,6,10,16,24$, and 35 leaves stage is shown in Fig. 6. Root system architecture depicted spatial configure of lateral roots, and root system in different stage showed very different architecture. There were only a small number (8 roots) of lateral roots at the 4 leaves stage, and these roots were very small and just existed within $5 \mathrm{~cm}$ soil layer. Roots in 6 leaves were much denser than that in 4 leaves. As the plant grew to 10 leaves, root number increased to 37; most roots spread in the top soil, and a few extended to deep soil. At the 35 leaves stage, there was only a slight increase in
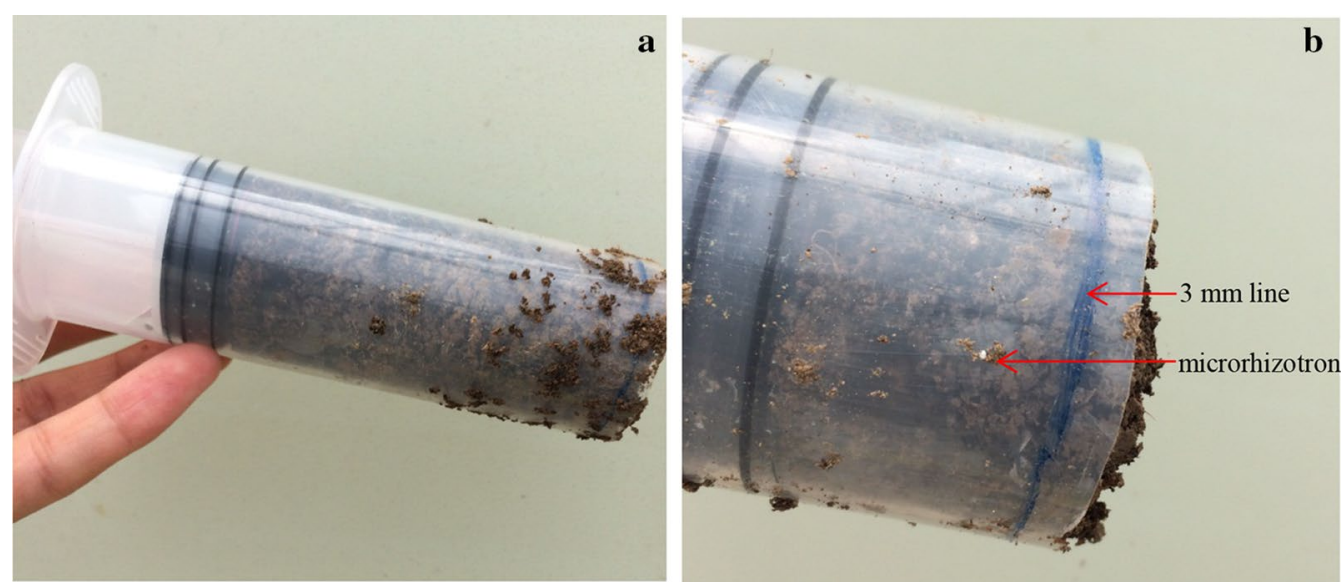

Fig. 5 Soil sampling of roots opposite to the camera in $3 \mathrm{~mm}$ 


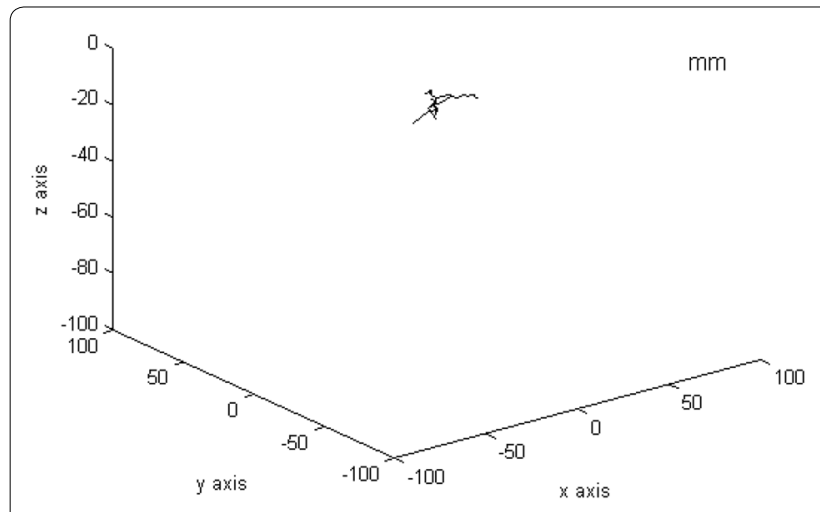

4 leaves

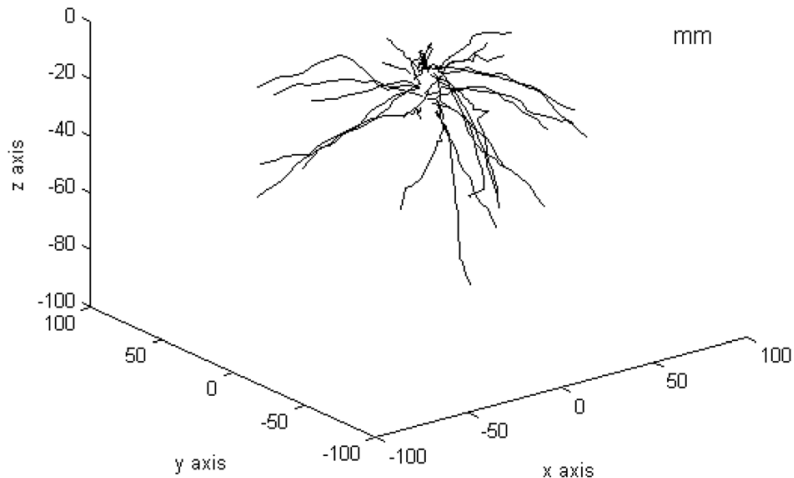

10 leaves

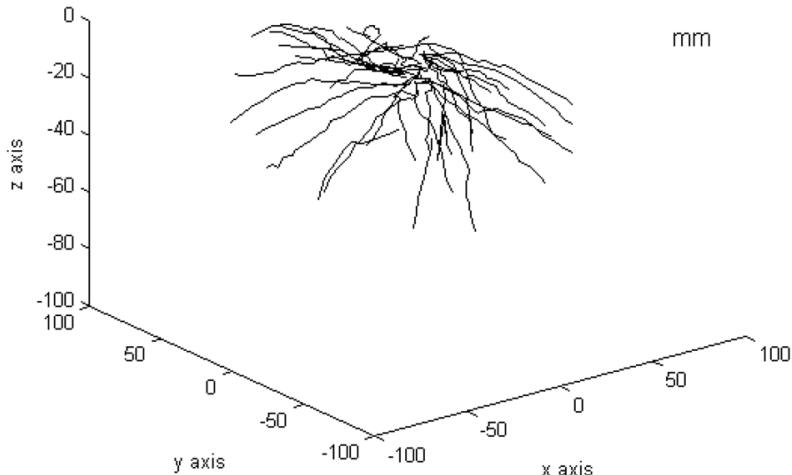

24 leaves

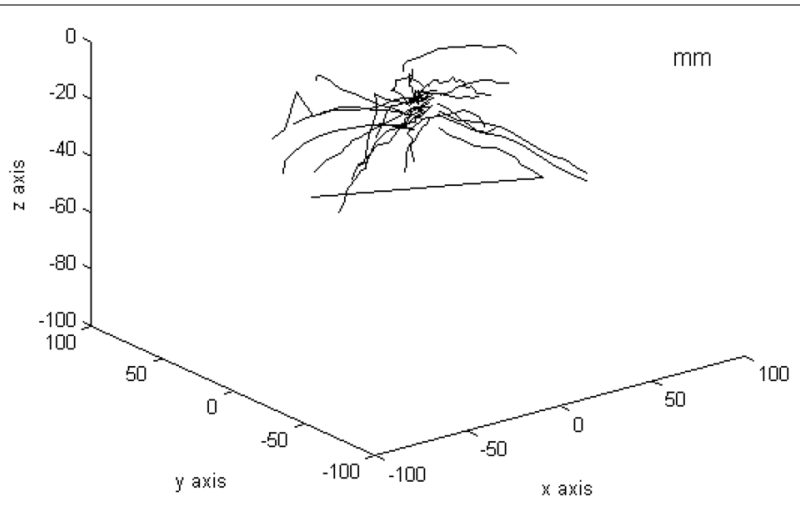

6 leaves

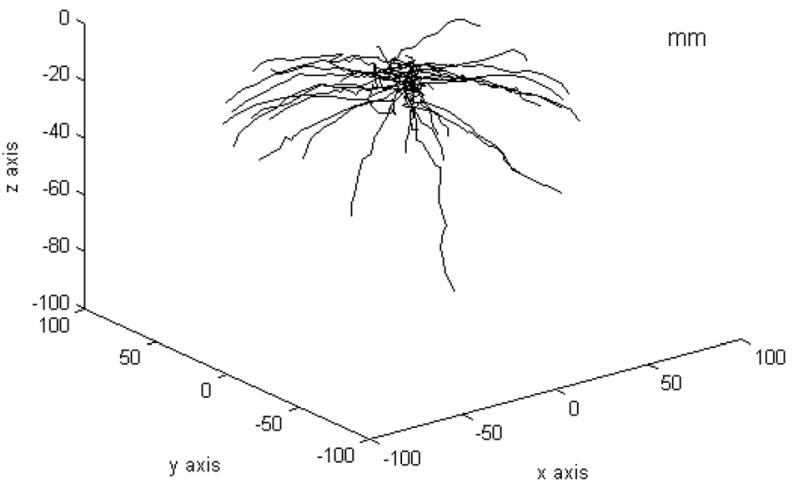

16 leaves

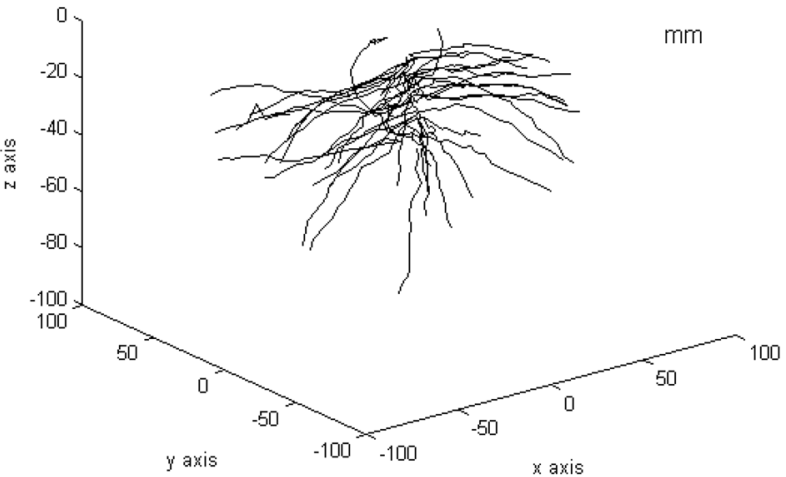

35 leaves

Fig. 6 Root system architecture 3D reconstruction. 4, 6, 10, 16, 24 and 35, are numbers of true leaves, and they were sampled in 7 days, 13 days, 19 days, 25 days, 31 days and 39 days after field planting 
root number, but a large number of roots extended to soil layer deeper than $5 \mathrm{~cm}$.

\section{Circumferential distribution of lateral roots after elongation}

From vertical view, lateral roots distributed radiative along primary root. Two perpendicular lines were introduced to divide the roots into 4 parts. Each line was about $45^{\circ}$ to initials of lateral roots. Interestingly, roots tended to gather in red arrow area, but in blue arrow area, roots were much less (Fig. 7). For understanding of spatial distribution of lateral roots after elongation, the circumferential gathering traits was quantified by calculating root length in red arrow area and in blue arrow area in Fig. 8. The result showed that lateral roots were highly focused in the red arrow area. The highest root length percentage of red arrow area in the 4 leaves stage reached $96 \%$. Although in 16 leaves stage, the percentage was a little lower $(84 \%)$ than the beginning, the average percentage was $90 \%$, indicating highly gathering of lateral roots.

Pepper root system is diarch, and the lateral roots initiate from a patch of protoxylem pole pericycle cell, and

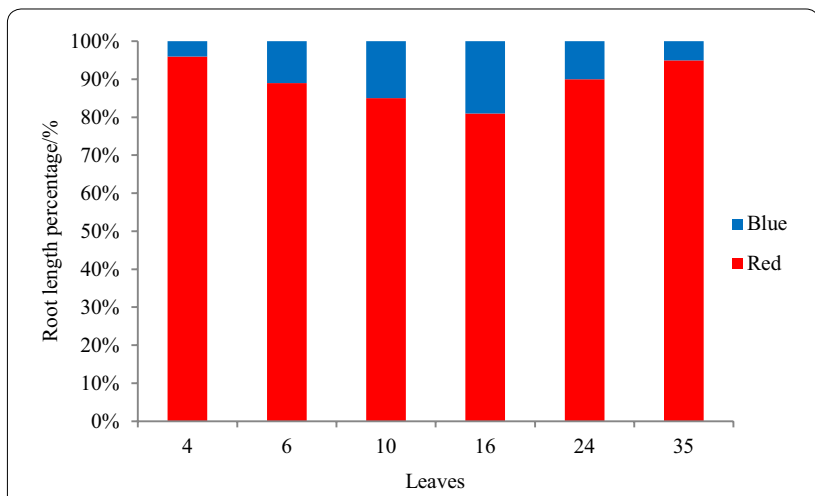

Fig. 8 Lateral root gathering rate in vertical direction. Red represented root length density in red arrow area and blue represented root length density in blue arrow area

are symmetrically located in two rows $[38,39]$. To some extent, our findings implied that spatial distribution of lateral roots after elongation was also restricted to some range, and restricted horizontal angle was a highly-conserved mechanism shared by most lateral roots.

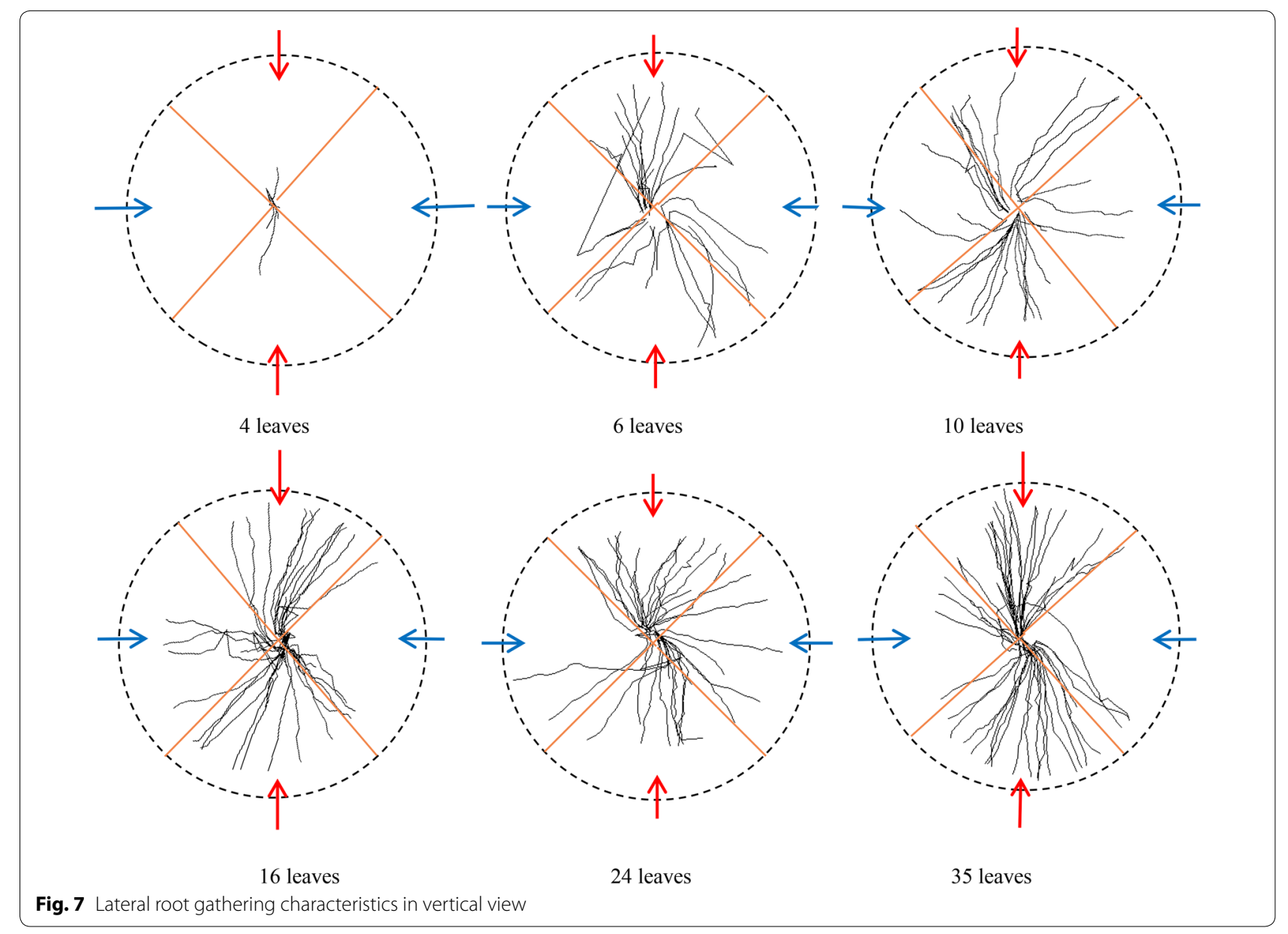




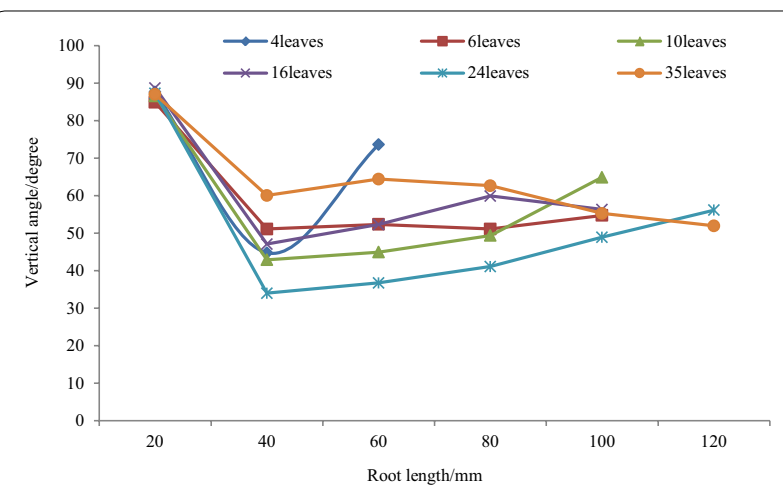

Fig. 9 Vertical angle of lateral roots

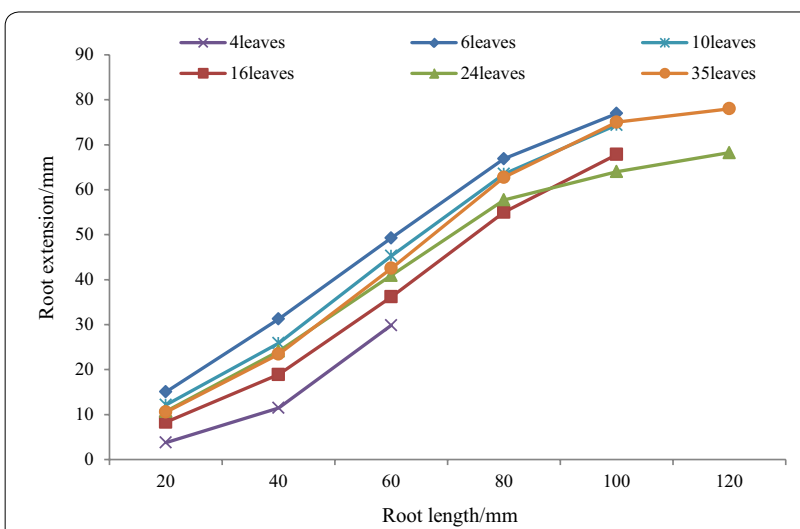

Fig. 10 Extension of lateral roots

\section{Vertical angle and root extension}

Vertical angle represented geotropism and deepen ability of lateral roots. As is depicted in Figs. 9 and 10, root length increased as plant leaves increased. The shortest root length was $60 \mathrm{~mm}$ in 4 leaves and extended to $120 \mathrm{~mm}$ in 35 leaves. For most lateral roots, vertical angles were between $80^{\circ}$ and $90^{\circ}$ at the initial position, almost perpendicular to the root center line. This indicated that lateral roots extended circumferentially at first to support the plant. Vertical angle since $20 \mathrm{~mm}$ was much lower than that of the beginning, and plant roots in different leaves showed different variation trend. Vertical angle at 4 leaves stage and 6 leaves stage seemed to be larger than that of 10 leaves stage, 16 leaves stage, and 24 leaves stage, but not that in 35 leaves stage. These differences might be caused by plant root development, since a smaller vertical implied lateral roots plunged into deep soil, which helped to search for water and nutrition, and to improve lodging resistance. Also, root phenotype was not only controlled by gene, but also by environment. Therefore, roots architecture may adapt appropriately to the environment. Although there was some difference as root exploring in soil, vertical angle of lateral roots was between $30^{\circ}$ and $60^{\circ}$ after elongation until $120 \mathrm{~mm}$.

Root extension was the distance of root to plant center line. Individually, root extension had some difference, for example, root extension in 4 leaves was the lowest, and that in 6 leaves was the highest. This is because plant had individual difference, and also different reflection to environments. Generally, lateral roots extension linearly increased when root length was less than $80 \mathrm{~mm}$. Then the increase slowed down, and reached peak value in root end. The longer the roots extent, the more water and nutrition it could access, and also more stable the plant would be. Therefore, the fast root extension in early days enabled a strong root basis for later development.

\section{Root length density distribution}

Root length density is heterogeneous in soil in different depths and radius. As is shown in Table 1, the root length density near the root center was the largest. With the increase of sampling radius, root length density decreased in general. The root system was concentrated in the shallow soil within $5 \mathrm{~cm}$ in 4 leaves, 6 leaves, and 10 leaves stages. When plants had more than 16 leaves, root system gradually appeared in the soil layer of $10 \mathrm{~cm}$, but compared with $5 \mathrm{~cm}$ soil layer, root length density was much smaller in $10 \mathrm{~cm}$ soil layer. Few roots were observed in depth more than $10 \mathrm{~cm}$.

Average root length density was only 0.09 in 4 leaves, and it increased to 1.081 in 24 leaves stage. Compared with average value, root length density in $R=10 \mathrm{~mm}$ was much greater, and root length density in $\mathrm{R}>40 \mathrm{~mm}$ was much smaller. Root length density between $R=20 \mathrm{~mm}$ and $R=40 \mathrm{~mm}$ was approximate to the average value. Interestingly, from time series root length density increased to the maximal value at 24 leaves, and then decreased. On one hand, this may be caused by circumferential expansion. As is shown in 35 leaves, although root length density near to the center decreased, it increased in large radius. On another hand, this may be related to root senescence and death, and the growth of the shoot, but still needs to be proved rigorously.

\section{Interception probability by different installation patterns according to root system architecture}

According to the analysis of root initiate principle and root elongation discussed before, 8 installation patterns (12 replicates) for microrhizotron were tested and verified to determine high probability of root interception. They were the permutation and combination of 2 horizontal angles $\left(45^{\circ}\right.$ and $\left.90^{\circ}\right), 2$ radiuses of microrhizotron to the root center line ( $30 \mathrm{~mm}$ and $60 \mathrm{~mm}$ ), and 2 vertical angles [18] $\left(30^{\circ}\right.$ and $\left.45^{\circ}\right)$. Each plant was equipped with 3 microrhizotrons, and the depth of all the presets 
Table 1 Root length density distribution

\begin{tabular}{|c|c|c|c|c|c|c|c|c|c|c|}
\hline \multirow{2}{*}{$\begin{array}{l}\text { Number } \\
\text { of leaves }\end{array}$} & \multirow[t]{2}{*}{ Depth (mm) } & \multicolumn{9}{|c|}{$\mathrm{R}(\mathrm{mm})$} \\
\hline & & 10 & 20 & 30 & 40 & 50 & 60 & 70 & 80 & Average \\
\hline \multirow[t]{2}{*}{4} & $0-50$ & 0.637 & 0.056 & 0.015 & 0.010 & 0 & 0 & 0 & 0 & 0.090 \\
\hline & 50-100 & 0 & 0 & 0 & 0 & 0 & 0 & 0 & 0 & 0 \\
\hline \multirow[t]{2}{*}{6} & $0-50$ & 2.023 & 1.639 & 0.623 & 0.462 & 0.170 & 0.081 & 0 & 0.058 & 0.632 \\
\hline & 50-100 & 0 & 0 & 0 & 0 & 0 & 0 & 0 & 0 & 0 \\
\hline \multirow[t]{2}{*}{10} & $0-50$ & 2.978 & 1.070 & 0.433 & 0.261 & 0.113 & 0.064 & 0.037 & 0.017 & 0.622 \\
\hline & $50-100$ & 0 & 0 & 0.011 & 0.001 & 0 & 0 & 0 & 0 & 0.002 \\
\hline \multirow[t]{2}{*}{16} & $0-50$ & 5.376 & 1.082 & 0.534 & 0.307 & 0.165 & 0.129 & 0.083 & 0.032 & 0.963 \\
\hline & 50-100 & 0.065 & 0.039 & 0.019 & 0 & 0 & 0 & 0.009 & 0.010 & 0.018 \\
\hline \multirow[t]{2}{*}{24} & $0-50$ & 5.599 & 2.067 & 0.618 & 0.224 & 0.082 & 0.041 & 0.019 & 0.000 & 1.081 \\
\hline & 50-100 & 0 & 0.097 & 0 & 0 & 0 & 0 & 0 & 0.007 & 0.013 \\
\hline \multirow[t]{2}{*}{35} & $0-50$ & 3.694 & 1.477 & 0.679 & 0.540 & 0.318 & 0.205 & 0.141 & 0.0516 & 0.888 \\
\hline & 50-100 & 0 & 0 & 0.026 & 0.011 & 0 & 0 & 0 & 0 & 0.005 \\
\hline
\end{tabular}

$\mathrm{R}$ referred to sampling radius

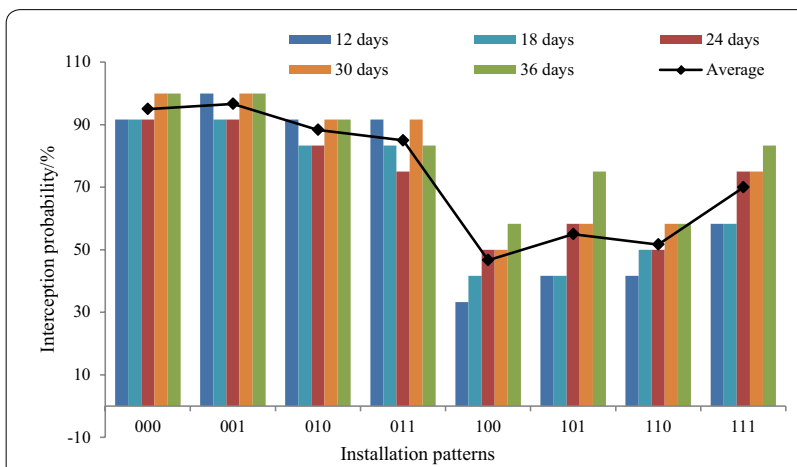

Fig. 11 Probabilities of root interception under different installation patterns. Notes The first number in the combined number represents horizontal angle of microrhizotron to referred plane, where 0 is $45^{\circ}$ and 1 is $90^{\circ}$. The second number in the combined number represents radius of microrhizotron to the root center line, where 0 is $30 \mathrm{~mm}$ and 1 is $60 \mathrm{~mm}$. The last number in the combined number represents vertical angle of microrhizotron to the root center line, where 0 is $30^{\circ}$ and 1 is $45^{\circ}$

was $50 \mathrm{~mm}$. It was convenient to observe root interception with microrhizotron every day, and in Fig. 9 we illustrated interception probability every 6 days.

As is shown in Fig. 11, probabilities of root interception under different installation patterns were greatly different. The highest interception probability appears in combination 001 with averaged value $96.7 \%$, followed by 000 with probability $95 \%$, and the lowest probability was only $46.7 \%$ in combination 100 . Combination $0 \times \times$ showed much higher interception probabilities than combination $1 \times \times$, indicating that a smaller horizontal angle will make the camera intercept with more roots. Interception probabilities in combination $\times \times 1$ was slightly higher than that of $\times \times 0$, implying installation of $45^{\circ}$ in vertical direction may be more proper for root interception in depth $50 \mathrm{~mm}$.

From time sequence, averaged interception probabilities increased slightly from 68.7 to $81.2 \%$ as days increased. The reason for this was that the development and elongation of roots improved interception with microrhizotron.

It was also obvious in the figure that if installation of microrhizotron were at random, interception probability might be only $73.5 \%$, while presetting according to root architecture features may increase this value to $96.7 \%$. The results proved that interception probability could be improved through proper and right preset of microrhizotrons according to roots architecture features.

\section{Comparing root traits acquired from microrhizotron with soil sampling}

As is shown in Tables 2 and 3, when root hair and very fine root were excluded, the relative error was $12.1 \%$ between microrhizotron and soil sampling in root length, and $15.4 \%$ in diameter. If root hair and very fine root was included, the relative increased high to $93.5 \%$ in root length and $48.9 \%$ in diameter. This was because most root hair and very fine root were broken and lost during soil sampling. So, in most cases, very fine roots could not be evaluated by soil sampling. However, excluding root hair and very fine root, average error of root length was $2.42 \mathrm{~mm}$. Average root diameter error was $0.05 \mathrm{~mm}$, and it was able to observe fine roots about $0.1 \mathrm{~mm}$ in diameter. 
Table 2 Comparison of root length acquired from microrhizotron and soil sampling ( $\mathrm{mm}$ )

\begin{tabular}{|c|c|c|c|c|c|c|c|c|c|c|c|}
\hline & $\mathrm{Ck}$ & $\operatorname{Tr} 1$ & $\operatorname{Tr} 2$ & Er1 & Er2 & & Ck & $\operatorname{Tr} 1$ & Tr2 & Er1 & Er2 \\
\hline 1 & 7.95 & 16.67 & 6.06 & 8.72 & 1.89 & 9 & 23.10 & 40.11 & 18.81 & 17.01 & 4.29 \\
\hline 2 & 11.00 & 28.75 & 9.83 & 17.75 & 1.17 & 10 & 25.10 & 39.90 & 20.60 & 14.80 & 4.50 \\
\hline 3 & 8.50 & 14.67 & 7.50 & 6.17 & 1.00 & 11 & 30.50 & 56.70 & 26.43 & 26.20 & 4.07 \\
\hline 4 & 8.60 & 20.88 & 7.23 & 12.28 & 1.37 & 12 & 33.50 & 61.80 & 33.40 & 28.30 & 0.10 \\
\hline 5 & 11.70 & 29.90 & 10.00 & 18.20 & 1.70 & 13 & 39.50 & 50.40 & 34.23 & 10.90 & 5.27 \\
\hline 6 & 13.80 & 30.66 & 12.80 & 16.86 & 1.00 & 14 & 18.00 & 33.98 & 17.60 & 15.98 & 0.40 \\
\hline 7 & 15.75 & 28.75 & 16.20 & 13.00 & 0.45 & 15 & 24.20 & 40.70 & 25.50 & 16.50 & 1.30 \\
\hline 8 & 19.45 & 32.67 & 15.65 & 13.22 & 3.80 & 16 & 40.95 & 79.40 & 34.54 & 38.45 & 6.41 \\
\hline
\end{tabular}

$\mathrm{Tr} 1$ represents root length including root hair acquired from microrhizotron, $\mathrm{Tr} 2$ represents root length excluding root hair acquired from microrhizotron. $\mathrm{Ck}$ represents root length acquired from soil sampling. Er1 is error between $\operatorname{Tr} 1$ and Ck, and Er2 is error between Tr2 and Ck

Table 3 Comparison of average diameter acquired from microrhizotron and soil sampling $\mathrm{mm}$

\begin{tabular}{|c|c|c|c|c|c|c|c|c|c|c|c|}
\hline & $\mathrm{Ck}$ & Tr1 & Tr2 & Er1 & Er2 & & Ck & Tr1 & Tr2 & Er1 & Er2 \\
\hline 1 & 0.14 & 0.06 & 0.1 & 0.08 & 0.04 & 9 & 0.54 & 0.36 & 0.6 & 0.18 & 0.06 \\
\hline 2 & 0.09 & 0.05 & 0.12 & 0.04 & 0.03 & 10 & 0.62 & 0.28 & 0.57 & 0.34 & 0.05 \\
\hline 3 & 0.11 & 0.05 & 0.09 & 0.06 & 0.02 & 11 & 0.76 & 0.39 & 0.71 & 0.37 & 0.05 \\
\hline 4 & 0.15 & 0.07 & 0.1 & 0.08 & 0.05 & 12 & 0.78 & 0.44 & 0.79 & 0.34 & 0.01 \\
\hline 5 & 0.34 & 0.11 & 0.43 & 0.23 & 0.09 & 13 & 0.88 & 0.43 & 0.88 & 0.45 & 0 \\
\hline 6 & 0.40 & 0.19 & 0.3 & 0.21 & 0.1 & 14 & 0.77 & 0.38 & 0.8 & 0.39 & 0.03 \\
\hline 7 & 0.44 & 0.23 & 0.4 & 0.21 & 0.04 & 15 & 0.68 & 0.33 & 0.67 & 0.35 & 0.01 \\
\hline 8 & 0.33 & 0.21 & 0.42 & 0.12 & 0.09 & 16 & 0.45 & 0.29 & 0.39 & 0.16 & 0.06 \\
\hline
\end{tabular}

$\mathrm{Tr} 1$ represents root length including root hair acquired from microrhizotron, $\mathrm{Tr} 2$ represents root length excluding root hair acquired from microrhizotron. $\mathrm{Ck}$ represents root length acquired from soil sampling. Er1 is error between $\operatorname{Tr} 1$ and Ck, and $\operatorname{Er} 2$ is error between $\operatorname{Tr} 2$ and $C k$

\section{Discussion}

The aim of this work was to adapt minirhizotron to a microrhizotron system that enables for multipoint observation for local and micro root changes, and investigated 3D distribution traits of Capsicum annuum under regular fertilizer and water strategy to ensure installation validity and rationality. Performances with different installation patterns of the microrhizotron system were validated, and root length and diameter were compared with soil samplings.

The microrhizotron system is a good compromise between the nondestructive detection and handling capacities of dynamic observation and the advantage of multipoint observation for roots. A big advantage of the microrhizotron is that they facilitate studying the response of roots in different positions, rather than watching in long tube and large diameter from top to bottom (from bottom to top), and obtaining roots image limited to the tube wall. For example, root length density in different depths and radius to root center line could be accurately acquired with the designed microrhizotron. Besides, it could also be applied to study on other root system traits (root hairs), and the plasticity and the dynamic alteration of root growth to environment and irrigation strategy.

In the root architecture reconstruction, it was obvious that capsicum root existed in shallow soil less than $10 \mathrm{~cm}$. Our result was not in consistence with Kong Q, in which root depth of pepper reached $40 \mathrm{~cm}$ [20]. This was attributed to different soil compactness in Kong Q's study $\left(1.4 \mathrm{~g} / \mathrm{cm}^{3}\right)$ and in our study $\left(1.55 \mathrm{~g} / \mathrm{cm}^{3}\right)$, since larger soil compactness made root harder to develop in depth [3, 40]. Disregarding the genetic variations, root development were affected by soil compactness and other soil environment (e.g. temperature, water holding capacity, hydraulic conductivity, porosity, pore size distribution and oxygen availability) [41, 42]. Therefore, for shallow root plants or roots constrained to shallow soil layer, microrhizotron would be more flexible, small and delicate for in situ observation.

Remarkably, from vertical view (Fig. 7), lateral roots are regularly initiating from two lines along primary. This agrees with the organization patterns of vascular bundles in dicot plants that vascular tissue exhibits diarch symmetry and only contains two xylem poles [38]. Quantification of root architecture in horizontal direction showed that root elongation was to some extent regulated to 
the two lines alone primary root. Although a small part slightly exceeded the angle, maybe caused by water and fertilizer inhomogeneity, or root competition, most lateral roots were constrained to an angle near to the initial position. In vertical direction, angles were larger at initial position and in shallow depth, and it became smaller when roots began to elongate. These results indicated that circumferential position and angles should be taken into account when presetting microrhizotron for dicot, Capsicum annuum especially in this research.

Installation has long been a problem in the use of minirhizotron [43]. Angle of the tube ranges from $0^{\circ}$ to $90^{\circ}$, although the installation angles of $30^{\circ}[44,45]$ and $45^{\circ}[46,47]$ occur more frequently, there is no standard or scientific proof by now. In this study, by measuring the root architecture traits, we proved that in depth $50 \mathrm{~mm}$, vertical angle $45^{\circ}$ performed better than vertical angle $30^{\circ}$ to intercept with roots. There were some difference between traditional minirhizotron and the adaptive minirhizotron described in this paper. For traditional minirhizotron, many studies have reported that installation of minirhizotron resulted in excessive root proliferation, particularly near the soil surface $[26,33,48]$. But in our study, no excessive root proliferation was observed. The new problem it faced was that microrhizotron sometimes failed to intercept with roots when preset at random. This may well be caused by the very small size of the microrhizotron, which reduce contact between roots and camera. Effective installation patterns to intercept with more roots were proved in this research. Our method was to quantify the spatial distribution of roots under conventional water and fertilizer treatments, and to install them based on that knowledge. 3D distribution traits of Capsicum annuum under regular fertilizer and water strategy could ensure installation validity and rationality effectively.

During plant root exploration in soil, plants may adapt their roots architecture to water, nutrients and environment. Therefore, observation dynamically over a long period involved in this process is crucial for improving plant growth under varying environmental stimuli. Our results clearly showed that microrhizotron is an ideal system for observation of roots compared with soil sampling when root hair and very fine root was excluded. Although root hair and very fine root cannot be evaluated with soil sampling method, it provides a multipoint, and nondestructive method to observe fine root and root hairs changes by day to day comparison. The limit of this study is that root observation with this kind of microrhizotron focused on local and subtle changes, and root system architecture traits were quantified with limited genotype and varieties. In the future study, observation of the root system architecture remains to combine microrhizotron with other methods, where the microrhizotron is used to focus on micro changes of roots, and method such as $\mathrm{X}-\mathrm{CT}$ is used to acquire $3 \mathrm{D}$ root architecture.

\section{Conclusion}

A new adaptive minirhizotron has been established for non-destructive and multipoint observation on roots, and its application and installation patterns has been suggested according to root architecture traits. The setup requires no sophisticated instruments, has a relatively small volume, and allowed in situ, rapid, non-destructive, multipoint analysis of root angle with minimal disturbance to plant growth. Root system architecture traits of Capsicum annuum was quantified by analyzing circumferential distribution, vertical angle, depth and root extension, which allowed for a more suitable and effective installation pattern of microrhizotrons. The preset validity could be highly improved by this method. The presented microrhizotron can be used to study a wide range of research questions on a small scale, for example, for quantitative trait locus analysis, root width changes, and root hair growth.

\section{Additional files}

Additional file 1. Script for root system architecture construction and analysis.

Additional file 2. Script for root image processing.

\section{Abbreviations}

X-CT: X-ray computed tomography; NMR: nuclear magnetic resonance.

\section{Authors' contributions}

The method was conceived by XW and WL. WL developed the devices and designed the experiments All scripts necessary for image processing were written by WL. Experiments and data analysis and root 3D reconstruction was performed by WL and FW. All authors read and approved the final manuscript.

\section{Author details}

${ }^{1}$ Department of Engineering College, Nanjing Agricultural University, Nanjing 210031, China. ${ }^{2}$ Jiangsu Province Engineering Laboratory for Modern Facilities Agricultural Technology and Equipment, Nanjing 210031, China.

\section{Acknowledgements}

We would like to express our sincere thanks to Mr Zhu Qi who have supported us in mechanical design and manufacture. We gratefully acknowledge the core financial support National Key R\&D Projects (2016YFD0200602-4) and Jiangsu Agricultural Science and Technology Independent Innovation Fund Project (CX(16)1002).

\section{Competing interests}

The authors declare that they have no competing interests.

\section{Availability of data and materials}

Original procedure and data for root system architecture and analysis is available on request. 


\section{Consent for publication}

All authors have given consent for the publication.

\section{Ethics approval and consent to participate}

Not applicable.

\section{Funding}

The work was funded by National Key R\&D Projects (2016YFD0200602-4), Postgraduate Research \& Practice Innovation Program of Jiangsu Province (KYCX18_0737), and Jiangsu Agricultural Science and Technology Independent Innovation Fund Project (CX(16)1002).

\section{Publisher's Note}

Springer Nature remains neutral with regard to jurisdictional claims in published maps and institutional affiliations.

Received: 25 September 2018 Accepted: 14 March 2019 Published online: 23 March 2019

\section{References}

1. Rogers ED, Benfey PN. Regulation of plant root system architecture: implications for crop advancement. Curr Opin Biotechnol. 2015;32(32C):93-8.

2. Iyer-Pascuzzi AS, Benfey PN. Imaging and analysis platform for automatic phenotyping and trait ranking of plant root systems. Plant Physiol. 2010;152(3):1148

3. Chen $X, L i Y, H e R$, et al. Phenotyping field-state wheat root system architecture for root foraging traits in response to environment $\times$ management interactions. Sci Rep. 2018;8(1):2642.

4. Mari CL, Kirchgessner N, Marschall D, et al. Rhizoslides: paper-based growth system for non-destructive, high throughput phenotyping of root development by means of image analysis. Plant Methods. 2014;10(1):13.

5. Morris EC, Griffiths M, Golebiowska A, et al. Shaping 3D root system architecture. Curr Biol. 2017;27(17):R919.

6. Lecompte F, Ozierlafontaine H, Pag SL. The relationships between static and dynamic variables in the description of root growth. Consequences for field interpretation of rooting variability. Plant Soil. 2001;236(1):19-31.

7. Koenig C, Wey H, Binkley T. Precision of the XCT 3000 and comparison of densitometric measurements in distal radius scans between XCT 3000 and XCT 2000 peripheral quantitative computed tomography scanners. J Clin Densitom. 2008;11(4):575.

8. Wen WL, Guo XY, Zhao CJ, et al. Crop roots configuration and visualization: a review. Sci Agric Sin. 2015;48:436-48.

9. Zhang J, Di W, Gong X, et al. Non-destructive detection of plant roots based on magnetic resonance imaging technology. Trans Chin Soc Agric Eng. 2012;28(8):181-5.

10. Kumi F, Mao HP, Hu JP, et al. Review of applying X-ray computed tomography for imaging soil-root physical and biological processes. Int J Agric Biol Eng. 2015;8(5):1-14.

11. Metzner R, Eggert A, Van Dusschoten D, et al. Direct comparison of MRI and X-ray CT technologies for 3D imaging of root systems in soil: potential and challenges for root trait quantification. Plant Methods. 2015:11(1):17.

12. Pflugfelder $D$, Metzner $R$, Dusschoten $D$, et al. Non-invasive imaging of plant roots in different soils using magnetic resonance imaging (MRI). Plant Methods. 2017;13(1):102.

13. Jahnke S, Menzel MI, Van Dusschoten DD, et al. Combined MRI-PET dissects dynamic changes in plant structures and functions. Plant J. 2010;59(4):634-44.

14. Bates GH. A device for the observation of root growth in the soil. Nature. 1937;139(3527):966-7.

15. Vamerali T, Bandiera M, Mosca G. Minirhizotrons in modern root studies. Berlin: Springer; 2012.
16. Mohamed A, Monnier Y, Mao Z, et al. An evaluation of inexpensive methods for root image acquisition when using rhizotrons. Plant Methods. 2017;13(1):11.

17. Chen $X$, Ding $Q$, Li Y, et al. Visualization of post-paddy wheat rooting system and 3-D fractal dimensions. Trans Chin Soc Agric Mach. 2015;46(3):328-35.

18. Bai WM, Cheng WX, Li LH. Applications of minirhizotron techniques to root ecology research. Acta Ecol Sin. 2005;25(11):3076-81.

19. Zhang Z, Li X, Zhang J, et al. Root growth dynamics of Caragana korshinskii using minirhizotrons. J Plant Ecol. 2006;30(3):457-64.

20. Kong QH, Li GY, Wang YH, et al. Influences of subsurface drip irrigation and surface drip irrigation on bell pepper growth under different fertilization conditions. Trans Chin Soc Agric Eng. 2010;26(7):21-5.

21. Tierney GL, Fahey TJ. Evaluating minirhizotron estimates of fine root longevity and production in the forest floor of a temperate broadleaf forest. Plant Soil. 2001;229(2):167-76.

22. Upchurch DR, Ritchie JT. Root observations using a video recording system in mini-rhizotrons. Agron J. 1983;75(6):1009-15.

23. Liao RW, Liu JM, An SQ, et al. Monitor of corn root growth in soil based on minirhizotron technique. Trans Chin Soc Agric Eng. 2010;26(10):156-61.

24. Rewald B, Ephrath JE. Minirhizotron techniques; 2013.

25. Johnson MG, Tingey DT, Phillips DL, et al. Advancing fine root research with minirhizotrons. Environ Exp Bot. 2001;45(3):263.

26. Taylor BN, Beidler KV, Strand AE, et al. Improved scaling of minirhizotron data using an empirically-derived depth of field and correcting for the underestimation of root diameters. Plant Soil. 2014;374(1-2):941-8.

27. Samson BK, Sinclair TR. Soil core and minirhizotron comparison for the determination of root length density. Plant Soil. 1994;161 (2):225-32.

28. Joslin JD, Wolfe MH. Disturbances during minirhizotron installation can affect root observation data. Soil Sci Soc Am J. 1999;63(1):218-21.

29. Itoh S. In situ measurement of rooting density by micro-rhizotron. Soil Sci Plant Nutr. 1985;31(4):653-6.

30. Majdi H. Root sampling methods: applications and limitations of the minirhizotron technique. Plant Soil. 1996;185(2):255-8.

31. Withington JM, Elkin AD, Bulaj B, et al. The impact of material used for minirhizotron tubes for root research. New Phytol. 2003;160(3):533-44.

32. Amato M, Lupo F, Bitella G, et al. A high quality low-cost digital microscope minirhizotron system. Comput Electron Agric. 2012;80(1):50-3.

33. Cai G, Vanderborght J, Klotzsche A, van der Kruk J, Neumann J, Hermes N, Vereecken $\mathrm{H}$. Construction of minirhizotron facilities for investigating root zone processes. Vadose Zone J. 2016;15(9):1-13.

34. Merrill SD, Upchurch DR. Converting root numbers observed at minirhizotrons to equivalent root length density. Soil Sci Soc Am J. 1994;58(4):289-302.

35. Lu W, Wang X, Wang F. Design and validation of in situ micro root observation system for tomato and pepper. Trans Chin Soc Agric Eng. 2018;34(22):12-8.

36. Gonzalez RC, Woods RE, Eddins SL. Digital image processing using MATLAB. London: McGraw Hill Education; 2013.

37. Wu CG, Luo XW. Application of computer vision technology to analysis of root pattern and architecture. Trans Chin Soc Agric Mach. 2000;31(3):63-6.

38. Chen $Y$, Xie Y, Song $C$, et al. A comparison of lateral root patterning among dicot and monocot plants. Plant Sci. 2018;274:201-11.

39. Möller BK, Xuan W, Beeckman T. Dynamic control of lateral root positioning. Curr Opin Plant Biol. 2017;35:1-7.

40. Hossne GA, Méndez J, Trujillo M, et al. Soil irrigation frequencies, compaction, air porosity and shear stress effects on soybean root development Acta Univ. 2015;25(1):22-30.

41. Lipiec J, Nosalewicz A, Pietrusiewicz J. Crop responses to soil physical conditions. Dordrecht: Springer; 2011.

42. Ma H, Evangelou MWH, Vontobel P, et al. Root growth and Zn uptake of three common crop plants in response to heterogeneity in soil texture and Zn distribution. Environ Exp Bot. 2016;127:45-54.

43. Iversen CM, Murphy MT, Allen MF, et al. Advancing the use of minirhizotrons in wetlands. Plant Soil. 2012:352(1-2):23-39. 
44. Wells $C E$, Eissenstat DM. Marked differences in survivorship among apple roots of different diameters. Ecology. 2001;82(3):882-92.

45. Phillips DL, Johnson MG, Tingey DT, et al. Minirhizotron installation in sandy, rocky soils with minimal soil disturbance. Soil Sci Soc Am J. 2000;64(2):761-4

46. Tingey DT, Phillips DL, Johnson MG. Optimizing minirhizotron sample frequency for an evergreen and deciduous tree species. New Phytol. 2003;157(1):155-61.
47. Edwards EJ, Benham DG, Marland LA, Fitter AH. Root production is determined by radiation flux in a temperate grassland community. Glob Change Biol. 2004;10(2):209-27.

48. Rytter RM, Rytter L. Quantitative estimates of root densities at minirhizotrons differ from those in the bulk soil. Plant Soil. 2012;350(1-2):205-20.
Ready to submit your research? Choose BMC and benefit from:

- fast, convenient online submission

- thorough peer review by experienced researchers in your field

- rapid publication on acceptance

- support for research data, including large and complex data types

- gold Open Access which fosters wider collaboration and increased citations

- maximum visibility for your research: over $100 \mathrm{M}$ website views per year

At BMC, research is always in progress.

Learn more biomedcentral.com/submissions 